\title{
A Novel Hybrid LDC Converter Topology for the Integrated On-Board Charger of Electric Vehicles
}

\author{
Vu-Hai Nam ${ }^{1,2}$, Duong-Van Tinh ${ }^{1}\left(\mathbb{D}\right.$ and Woojin Choi ${ }^{1, *}$ \\ 1 Department of Electrical Engineering, Soongsil University, Seoul 06978, Korea; \\ nam.vhn91@gmail.com (V.-H.N.); Tinhduong16082401@gmail.com (D.-V.T.) \\ 2 Control Techniques and Innovation Laboratory for Electric Vehicles, School of Electrical Engineering, \\ Hanoi University of Science and Technology, Hanoi 10000, Vietnam \\ * Correspondence: cwj777@ssu.ac.kr; Tel.: +82-2-820-0652
}

Citation: Nam, V.-H.; Tinh, D.-V.; Choi, W. A Novel Hybrid LDC Converter Topology for the Integrated On-Board Charger of Electric Vehicles. Energies 2021, 14, 3603. https://doi.org/10.3390/ en14123603

Academic Editors: Rui Xiong and Nicu Bizon

Received: 21 May 2021

Accepted: 15 June 2021

Published: 17 June 2021

Publisher's Note: MDPI stays neutral with regard to jurisdictional claims in published maps and institutional affiliations.

Copyright: (c) 2021 by the authors. Licensee MDPI, Basel, Switzerland. This article is an open access article distributed under the terms and conditions of the Creative Commons Attribution (CC BY) license (https:// creativecommons.org/licenses/by/ $4.0 /)$.

\begin{abstract}
Recently, the integrated On-Board Charger (OBC) combining an OBC converter with a Low-Voltage DC/DC Converter (LDC) has been considered to reduce the size, weight and cost of DC-DC converters in the EV system. This paper proposes a new integrated OBC converter with V2G (Vehicle-to-Grid) and auxiliary battery charge functions. In the proposed integrated OBC converter, the OBC converter is composed of a bidirectional full-bridge converter with an active clamp circuit and a hybrid LDC converter with a Phase-Shift Full-Bridge (PSFB) converter and a forward converter. ZVS for all primary switches and nearly ZCS for the lagging switches can be achieved for all the operating conditions. In the secondary side of the proposed LDC converter, an additional circuit composed of a capacitor and two diodes is employed to clamp the oscillation voltage across rectifier diodes and to eliminate the circulating current. Since the output capacitor of the forward converter is connected in series with the output capacitor of the auxiliary battery charger, the energy from the propulsion battery can be delivered to the auxiliary battery during the freewheeling interval and it helps reduce the current ripple of the output inductor, leading to a smaller volume of the output inductor. A $1 \mathrm{~kW}$ prototype converter is implemented to verify the performance of the proposed topology. The maximum efficiency of the proposed converter achieved by the experiments is $96 \%$.
\end{abstract}

Keywords: active clamp; hybrid converter; LDC converter; PSFB converter; minimized circulating current; Zero-Voltage Switching (ZVS); integrated OBC

\section{Introduction}

The energy storage system in Electric Vehicles (EVs) and Plug-in Hybrid Electric Vehicles (PHEVs) normally consist of two kinds of batteries (400 V high voltage battery and $24 \mathrm{~V}$ or $48 \mathrm{~V}$ low voltage battery). One is the propulsion battery to provide a high DC voltage for the electric motor and the other is the auxiliary battery to supply a low DC voltage for the low voltage electric devices such as the lighting, entertainment, signaling circuit and audio systems. In order to charge those two batteries, in general, two different converters are required: an On-Board Charger (OBC) for the propulsion battery and a LowVoltage DC/DC Converter (LDC) converter for the auxiliary battery. In the conventional DC-DC converter systems on EVs or PHEVs, since these two converters operate separately, the size of the DC-DC converter system becomes bulky. In order to cope with this problem, an integrated $\mathrm{OBC}$ has been introduced by combining the OBC converter with the LDC converter to achieve a smaller volume, lighter weight and lower cost. An integrated OBC converter can perform three different functions: (1) charge operation from Grid-to-Vehicle (G2V), (2) discharge operation from Vehicle-to-Grid (V2G) [1] and (3) charge operation from Propulsion Battery to Auxiliary Battery (P2A).

The OBC converter can be classified into two categories, the two-stage OBC converter and the single-stage OBC converter. In the two-stage OBC converter, a non-isolated boost converter is popularly used for the PFC stage [2-5]. For the DC-DC converter of 
the two-stage OBC, the isolated converter topologies such as Phase-Shifted Full-Bridge (PSFB) converters [6-14], Dual Active Full-Bridge (DAFB) converters [15] and resonant converters [16] are preferred. In reference [14], a ZVZCS PSFB converter is introduced using an active clamp circuit in the secondary side to reduce the circulating current between the leading and lagging leg switches to improve the efficiency of the converter. In the meanwhile, single-stage OBC converters have been introduced to reduce the number of components, the size and the weight $[17,18]$. In single-stage OBC converters, the ACDC converter and the DC-DC converter are combined to utilize a single inductor for all operation modes (braking, charging and driving). However, the utilizing of the single inductor results in the dc-link capacitor containing low-frequency voltage ripple and causes an oscillating current of the battery. In addition, there is a concern in use of single-stage OBC converters in terms of safety since they do not provide galvanic isolation between the grid and battery.

Integrated OBC converters have been introduced to minimize the size and volume of DC-DC converters in EV systems, which are critical factors to improve the fuel economy of the EV. However, one of the main issues in the integrated OBC converter is that it is not easy to make the LDC converter in the integrated OBC converter perform as well as the independent LDC converter does. In [19-22], a LLC resonant converter was employed as the LDC converter to charge a low voltage battery. However, due to the large input voltage variation of the propulsion battery, typically from $250 \mathrm{~V}$ to $420 \mathrm{~V}$, the LLC resonant converter needs to vary its switching frequency in a wide range, which results in a low efficiency. Reference [23] introduced a multifunctional onboard charger using two FullBridge (FB) converters connected in series. However, the efficiency of the LDC converter is not good enough due to the high conduction losses resulting from a long connection path through many components of two series FB converters. In addition, since the turns-ratio of the transformer of this converter is selected by nearly one for bidirectional application, the voltage step-down ratio mainly depends on the duty cycle of the full-bridge converter. Hence, the circulating current of the converter becomes larger as the duty is smaller, thereby leading to a lower efficiency of the converter due to the higher conduction losses. In [24], the tertiary winding of the transformer with a high number of turns is adopted to avoid operation with a small duty cycle. However, it is disadvantageous in that it may lose the soft-switching characteristics when the voltages at two secondary windings of the transformer do not match. In [25], an integrated OBC converter is proposed with an OBC converter based on a Voltage Current-Fed Full-Bridge (VCFFB) structure. The soft-switching condition can be guaranteed over a wide range of load conditions. Based on experimental results, the converter in [25] shows a simpler structure and higher efficiency compared to the converter in $[23,24]$. Nevertheless, when the power is delivered from the propulsion battery to the auxiliary battery, this converter operates as a current-fed converter with an input inductor, which causes an increase in the voltage of the transformer. Therefore, a higher turns ratio of the transformer is required to compensate for the surplus voltage by the input inductor. In addition, the rectifier diodes suffer from the recovery current, which results in a low performance of the converter in the high current operation.

In this paper, a novel integrated OBC converter is proposed as shown in Figure 1. The OBC that performs G2V and V2G functions is integrated with the LDC converter introduced in [25] to solve the problems such as the surplus voltage caused by the inductor and the high conduction loss during the P2A operation. Here, the main focus is illustrating the charge operation of the LDC converter when it charges the auxiliary battery from the propulsion battery.

This paper includes five sections: Section 1 shows the introduction of the research and Section 2 provides a description about the operating principle of the proposed converter. All the features and design considerations for the proposed converter to get soft switching are presented in Section 3. In Section 4, a prototype $1 \mathrm{~kW}$ converter has been implemented to verify performances of the proposed converter. Finally, the conclusion is given in Section 5 . 


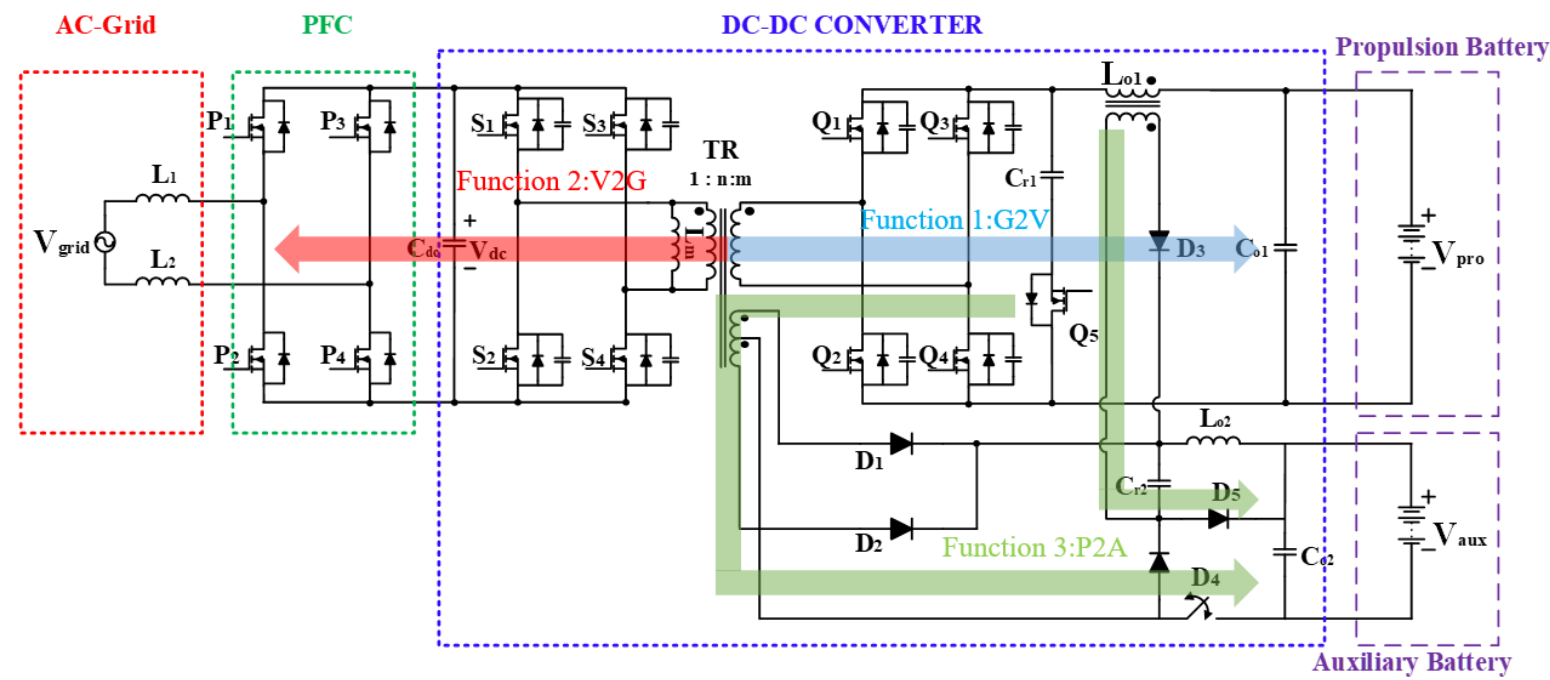

Figure 1. Proposed integrated OBC.

\section{Operation of the Proposed Integrated OBC}

The circuit diagram of the LDC converter in the proposed integrated OBC is shown in Figure 2. The primary side is composed of an input capacitor $C_{01}$, an active clamp circuit with $C_{r 1}$ and an active switch $Q_{5}$ and a PSFB converter with switches $Q_{1}, Q_{2}, Q_{3}$ and $Q_{4}$. The transformer of the PSFB converter is $T R_{1}$ with a magnetizing inductance $L_{m 1}$, a leakage inductance $L_{L K 1}$ and a turns ratio of $n_{1}: 1$. The transformer of the forward converter is $T R_{2}$ with a magnetizing inductance $L_{m 2}$, a leakage inductance $L_{L K 2}$ and a turns ratio of $n_{2}: 1$. The secondary side of the PSFB converter includes rectifier diodes $D_{1}$ and $D_{2}$, a passive snubber circuit composed of $C_{r 2}, D_{4}$ and $D_{5}$. The capacitor $C_{r 2}$ connected in parallel with the output inductor $L_{\mathrm{O} 2}$ also plays a function as an output capacitor of the forward converter and reduces the current ripple of the output. As mentioned earlier, the focus is on explaining the operation of the LDC of the proposed integrated OBC. Here, a half of the switching cycle of the proposed converter is divided into seven modes and the operation is explained in detail since the other half is symmetric. The key waveforms and the equivalent circuits of each operation mode are shown in Figures 3 and 4, respectively. For the sake of simplicity, all of the circuit components are ideal except the output capacitance of the switch and all of the output capacitances of the switches are assumed to be same.

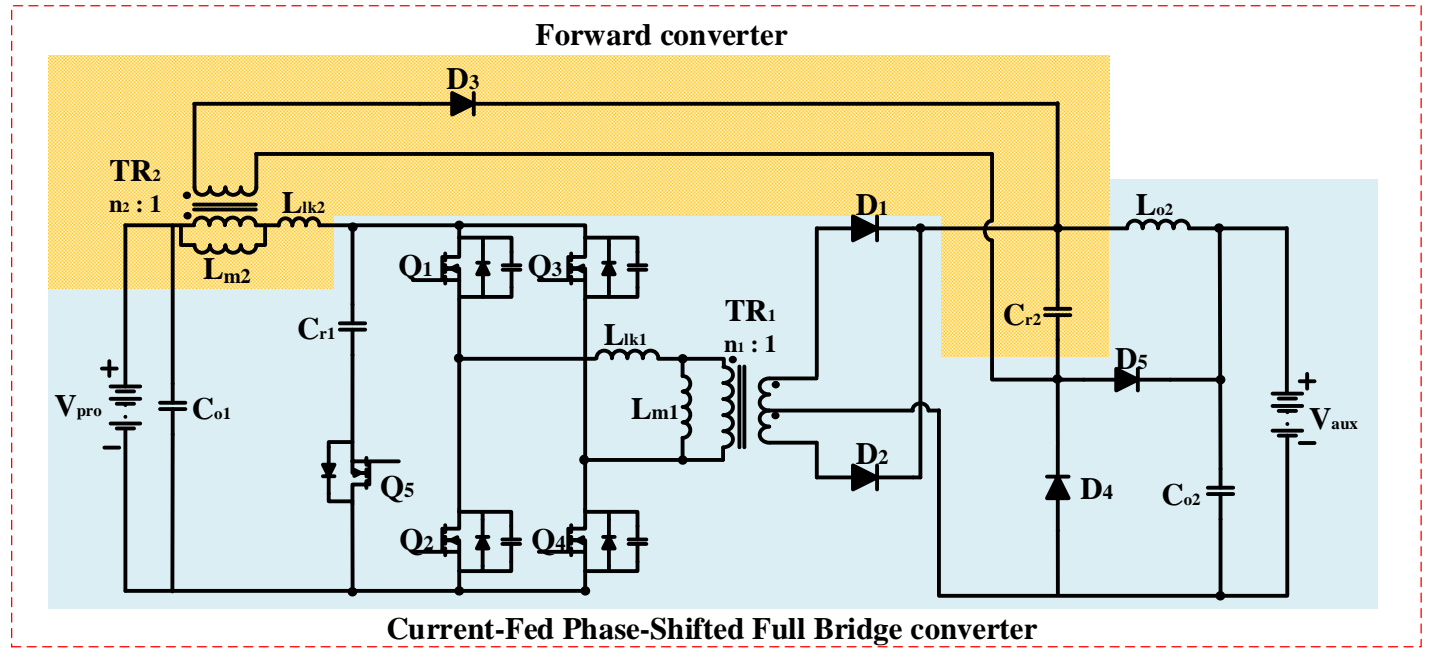

Figure 2. LDC converter of the proposed integrated OBC. 


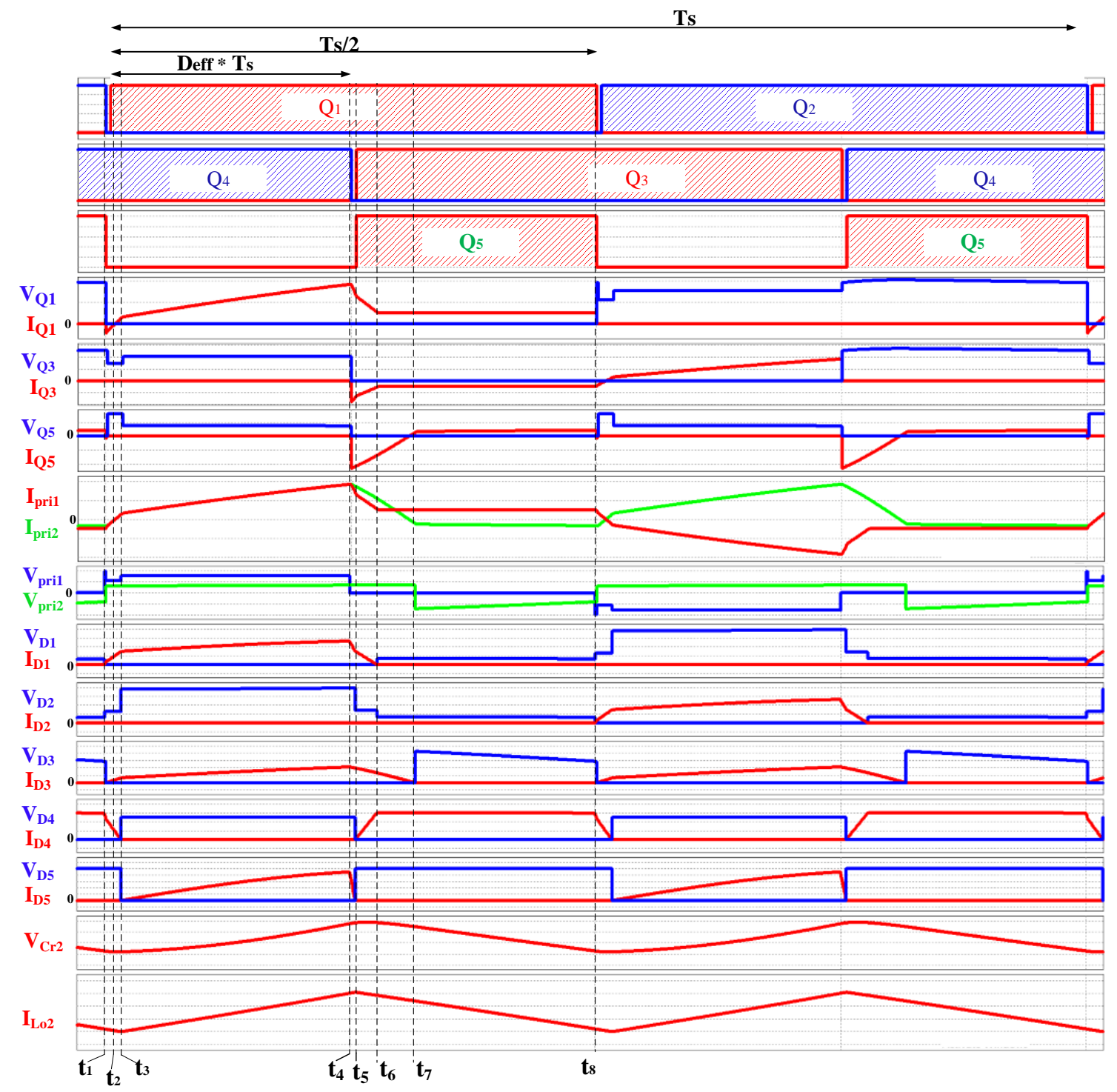

Figure 3. Key waveforms of proposed LDC converter.

Mode $1\left[t_{1}-t_{2}\right]$, Figure 4 a.

At $t=t_{1}, Q_{4}$ is on and $Q_{3}$ is off. $Q_{2}$ and $Q_{5}$ turn off, and their parasitic capacitors are charged. The parasitic capacitor of $Q_{1}$ is discharged and its body diode is forward biased creating ZVS turn-on condition for $Q_{1}$. The power is transferred to load through the transformers $T R_{1}$ and $T R_{2}$.

In the secondary side, diodes $D_{2}$ and $D_{5}$ are reverse biased. $D_{1}, D_{3}$ and $D_{4}$ are forward biased. The resonant capacitor $C_{r 2}$ resonates with output inductor $L_{O 2}$ and discharges the energy to the output.

Mode $2\left[t_{2}-t_{3}\right]$, Figure $4 \mathrm{~b}$.

At $t=t_{2}, Q_{1}$ turns on while $Q_{4}$ is already on in mode $1 . Q_{2}, Q_{3}$ and $Q_{5}$ are off. The body diode of $Q_{1}$ is reverse biased and the current flows through $Q_{1}$. The secondary side works in the same fashion as in mode 1 . Due to the resonance between $C_{r 2}$ and $L_{\mathrm{O} 2}$, the current flowing through $D_{4}$ decreases to zero and achieves ZCS turn-off condition for $D_{4}$ at the end of this mode. 


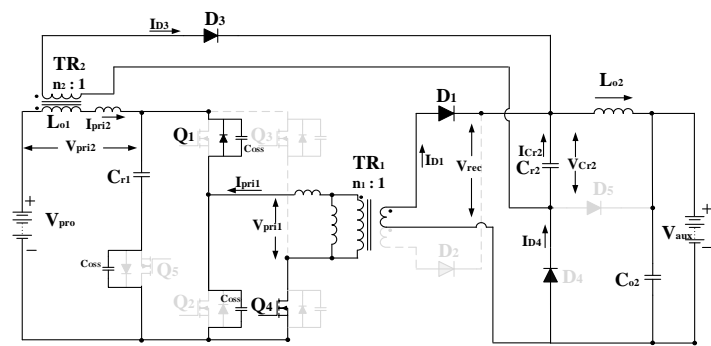

(a) Mode 1: $t_{1}-t_{2}$

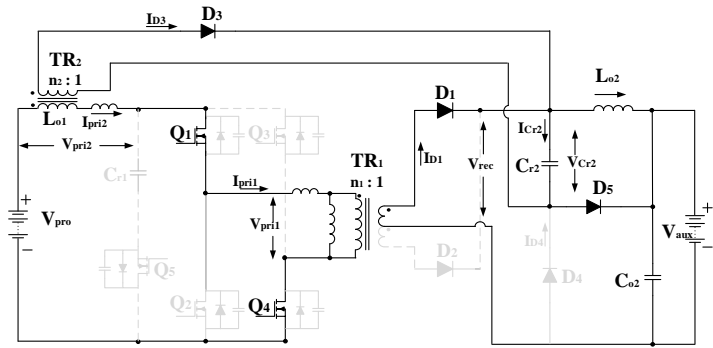

(c) Mode 3: $t_{3}-t_{4}$

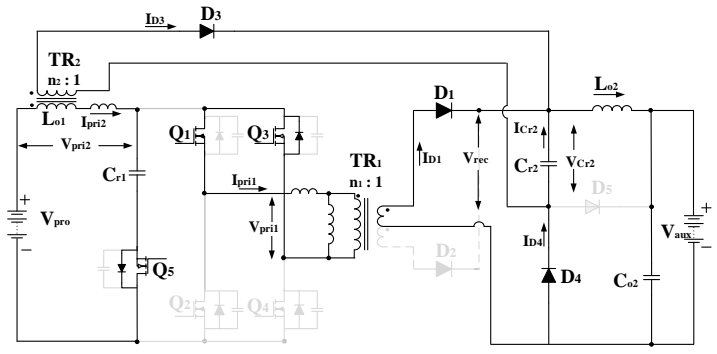

(e) Mode 5: $\mathrm{t}_{5}-\mathrm{t}_{6}$

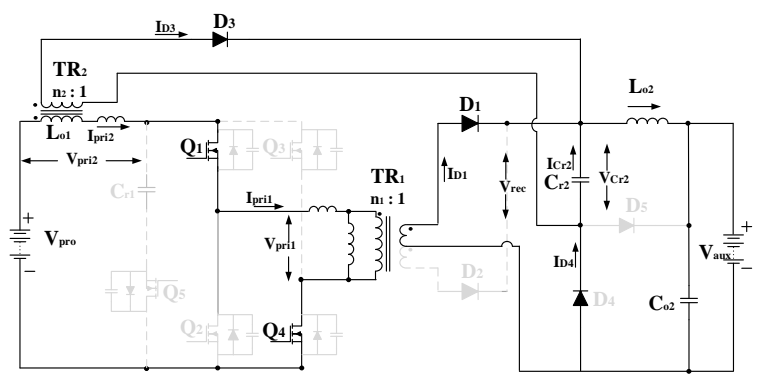

(b) Mode 2: $\mathrm{t}_{2}-\mathrm{t}_{3}$

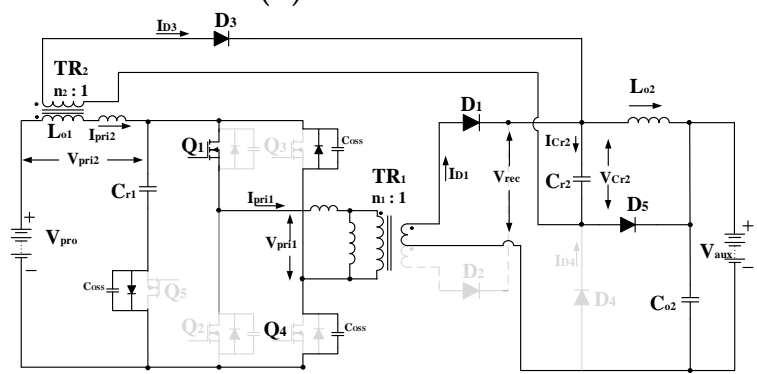

(d) Mode 4: $\mathrm{t}_{4}-\mathrm{t}_{5}$

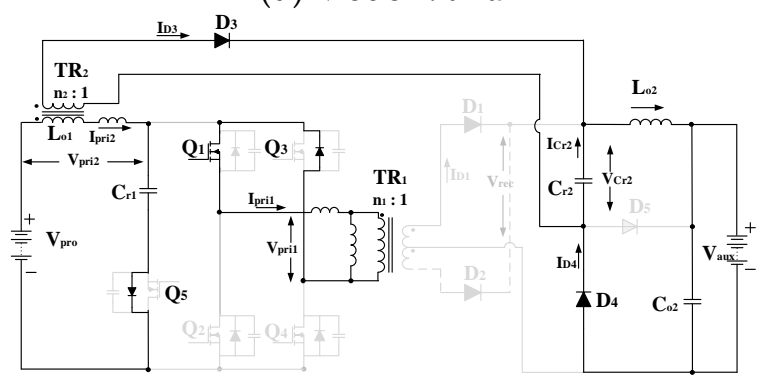

(f) Mode 6: $\mathrm{t}_{6}-\mathrm{t}_{7}$

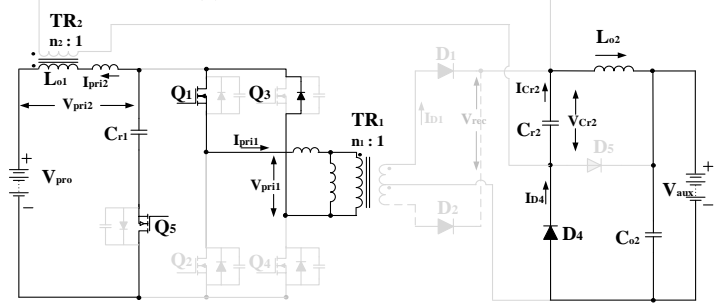

(g) Mode 7: t7-t8

Figure 4. Equivalent circuits of proposed LDC converter.

Mode $3\left[t_{3}-t_{4}\right]$, Figure $4 \mathrm{c}$.

At $t=t_{3}, Q_{1}$ and $Q_{4}$ are on. $Q_{2}, Q_{3}$ and $Q_{5}$ are off. The input power is delivered to the output by both converters. In the forward converter, the primary current $i_{\text {pri2( } t)}$ flows through the transformer $T R_{2}$ and charges the resonant capacitor $C_{r 2}$ in the secondary side. In the PSFB converter, the primary current $i_{\text {pri1 }}$ flows through switches $Q_{1}, Q_{4}$ and transformer $T R_{1}$. The currents $i_{\text {pri1 }}$ and $i_{\text {pri2 }}(t)$ are determined as below.

$$
\begin{gathered}
i_{\text {pri1 }}(t)=\frac{1}{n_{1}}\left(i_{L_{O 2}}(t)+\frac{V_{\text {pri1 }}-n_{1} V_{\text {Aux_bat }}}{n_{1} L_{O 2}}\left(t-t_{1}\right)\right) \\
i_{\text {pri2 }}(t)=\frac{1}{n_{2}}\left(i_{L_{O 2}}(t)+\frac{V_{C r 2}(t)}{L_{O 2}}\left(t-t_{1}\right)\right)
\end{gathered}
$$

where $V_{\text {pri1 } 1}$ is the primary winding voltage of the transformer $T R_{1}, V_{a u x \_b a t}$ is the auxiliary battery voltage, $i_{p r i 1}$ is the primary current of the forward converter, $\bar{i}_{p r 2}$ is the primary 
current of the PSFB converter, $i_{\mathrm{Lo} 2}$ is the current flow through the output inductor $L_{o 2}$, and $V_{C r 2}$ is the voltage of capacitor $C_{r 2}$.

In the secondary side, diode $D_{4}$ is reverse biased and $D_{5}$ is forward biased to charge the resonant capacitor $C_{r 2}$ and the output capacitor $C_{o 2}$, respectively. The rectifier bridge voltage $V_{\text {rec }}(t)$ can be calculated as in (3).

$$
V_{\text {rec }}(t)=V_{\text {Aux_bat }}+V_{C r 2}(t)
$$

where $V_{\text {rec }}$ is the rectifier voltage of the PSFB converter.

Mode $4\left[t_{4}-t_{5}\right]$, Figure $4 \mathrm{~d}$.

At $t=t_{4}$, the switch $Q_{4}$ turns off. The parasitic capacitor of $Q_{3}$ is discharged. In the forward converter, the current of transformer $T R_{2}$ flows through the active clamp circuit including capacitor $C_{r 1}$ and the body diode of $Q_{5}$. The capacitor $C_{r 1}$ resonates with the leakage inductor $L_{L K 2}$. Since the parasitic capacitor of $Q_{4}$ is charged and that of $Q_{3}$ is discharged, the ZVS turn-on condition for $Q_{3}$ is achieved. The voltage $V_{\text {Coss_Q3 }}$ across $Q_{3}$ can be found as shown in (4).

$$
V_{C_{O S S_{-} Q_{3}}}=V_{\text {pri1 }}(t)-Z_{1} i_{\text {pri1 }}\left(t_{4}\right) \sin \omega\left(t-t_{4}\right)
$$

where $\omega$ and $Z_{1}$ can be calculated using (5) and (6), respectively.

$$
\begin{gathered}
\omega=\frac{1}{\sqrt{\left(L_{L K 1}+L_{m 1}\right) C_{O S S}}} \\
Z_{1}=\frac{L_{L K 1}+L_{m 1}}{C_{O S S}}
\end{gathered}
$$

In the secondary side, the current commutation occurs from $D_{1}$ to $D_{4}$ and resonant capacitor $C_{r 2}$. The current $i_{D 1}$ flowing through $D_{1}$ can be determined as follows.

$$
i_{D_{1}}(t)=i_{L_{O 2}}\left(t_{4}\right)-\frac{V_{C r 2}+V_{A u x \_b a t}}{L_{O 2}}\left(t-t_{4}\right)
$$

Mode $5\left[t_{5}-t_{6}\right]$, Figure $4 \mathrm{e}$.

At $t=t_{5}, Q_{3}$ and $Q_{5}$ are turned on while $Q_{1}$ is on. The body diodes of $Q_{3}$ and $Q_{5}$ and diodes $D_{1}, D_{3}$ and $D_{4}$ are forward biased. The other diodes are reverse biased. The resonant capacitor $C_{r 2}$ is discharged through the diodes $D_{1}$ and $D_{4}$. In the forward converter, the resonance between the capacitor $C_{r 1}$ and the leakage inductor $L_{L K 2}$ continues. The power is transferred to the secondary side through the transformer $T R_{2}$ of the forward converter.

The primary current $i_{\text {pri } 1}(\mathrm{t})$ of the PSFB converter can be expressed using (8).

$$
i_{\text {pri1 }}(t)=i_{m 1}\left(t_{5}\right)=\frac{V_{p r i 1}}{L_{m 1}}\left(t-t_{5}\right)
$$

where $i_{m 1}$ is the magnetizing current of the PSFB converter.

The current through diode $D_{1}$ can be expressed using (9).

$$
i_{D_{1}}(t)=i_{\text {Lo2 }}\left(t_{5}\right)-\frac{V_{A u x-b a t}}{L_{O 2}}\left(t-t_{5}\right)
$$

Mode $6\left(t_{6}-t_{7}\right)$, Figure $4 \mathrm{f}$.

At $t=t_{6}$, the diode $D_{1}$ is reverse biased as the current commutation from $D_{1}$ to $D_{4}$ is completed. In the primary side of the PSFB converter, $Q_{1}$ is on and the body diode of $Q_{3}$ is forward biased. The primary current of the PSFB converter is circulating and kept constant. The forward converter operates the same as in mode 5 .

In the secondary side, diodes $D_{3}$ and $D_{4}$ are forward biased. Due to the discharge of $L_{\mathrm{O} 2}$, the current through $D_{3}$ decreases to zero gradually. At the end of this mode, the diode $D_{3}$ is turned off with ZCS. 
Mode $7\left(t_{7}-t_{8}\right)$, Figure $4 \mathrm{~g}$.

At $t=t_{7}$, the body diode of $Q_{5}$ is reverse biased and the current flows through the $Q_{5}$. In the forward converter, the capacitor $C_{r 1}$ resonates with the inductance of the transformer $T R_{2}$ and the resonant current resets it, thereby eliminating the need for tertiary winding of the forward converter. The primary current of the PSFB converter is still circulated through the $Q_{1}$ and the body diode of $Q_{3}$. In this mode, there is no power transferred to the secondary side. As in mode 6 , the diode $D_{4}$ is still forward biased and the energy in the capacitor $C_{r 2}$ is discharged to the load. After mode 7 the other half of the switching cycle operates in a symmetric fashion.

\section{Features and Design Consideration}

\subsection{Features of the Proposed Converter}

\subsubsection{High Step-Down Voltage Conversion Ratio}

The proposed LDC converter is a combination of a forward converter and a PSFB converter with a high step-down voltage conversion ratio as compared to the converter introduced in [24]. In order to explain the characteristics of the proposed LDC converter in terms of voltage conversion ratio its simplified circuit model is shown in Figure 5.

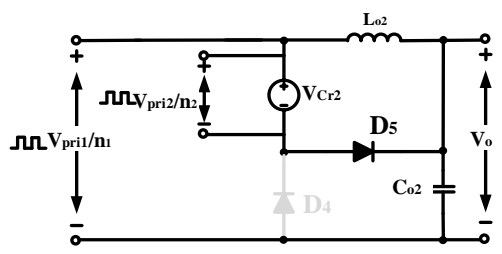

(a) Mode 1 Mode 3

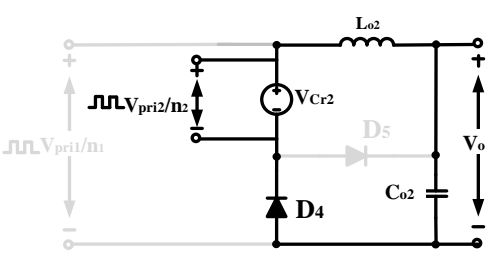

(b) Mode 4 Mode 6

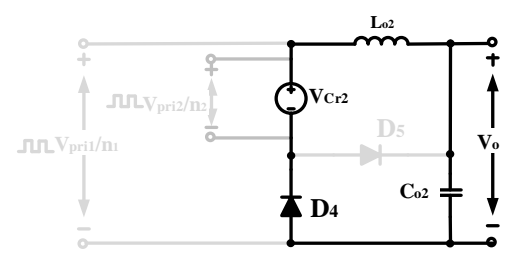

(c) Mode 7

Figure 5. Simplified circuit model of the LDC converter: (a) power transfer mode in both converters, (b) power transfer mode in forward converter and freewheeling mode of PSFB converter, (c) freewheeling mode of both converters.

Based on the equivalent circuit shown in Figure 5a. the output voltage $V_{o}$ of the proposed converter can be derived as (10).

$$
V_{o}=\frac{V_{p r i 1}}{n_{1}} D_{e f f}+\frac{V_{p r i 2}}{n_{2}}\left(D_{e f f}+D^{\prime}\right)
$$

where $D_{\text {eff }}$ is the effective duty cycle of the PSFB converter and $D^{\prime}$ is the time period from mode 4 to mode $6\left(t_{4}-t_{6}\right)$ when the resonant capacitor $C_{r 2}$ resonates with the leakage inductor $L_{L K 2}$ of the transformer $T R_{2}$ as shown in (11).

$$
D^{\prime}=\frac{1}{4} \frac{f_{s}}{2 \pi \sqrt{L_{L K 2} C_{r 2}}}
$$

The voltage conversion ratio of the proposed converter is decided by the turns ratio for $n_{1}$ and $n_{2}$ as shown in Figure 6.

The voltage applied to the primary winding of each transformer can be expressed as in (12) and (13), respectively.

$$
\begin{aligned}
& V_{\text {pri2 }}=\frac{n_{2}^{2}}{n_{1}^{2}+n_{2}^{2}} V_{i n} \\
& V_{\text {pri1 }}=\frac{n_{1}^{2}}{n_{1}^{2}+n_{2}^{2}} V_{i n}
\end{aligned}
$$

where $V_{\text {pri2 }}$ is the primary winding voltage of the transformer $T R_{2}$ and $V_{P r i 1}$ is the primary winding voltage of the transformer $\operatorname{Tr}_{1}$. 
By combining (12) and (13), the voltage conversion ratio $M_{\text {proposed }}$ of the proposed converter can be calculated as in (14).

$$
M_{\text {proposed }}=\frac{V_{o}}{V_{\text {in }}}=\frac{1}{n_{1}^{2}+n_{2}^{2}}\left(n_{1} D_{\text {eff }}+n_{2}\left(D_{\text {eff }}+D^{\prime}\right)\right)
$$

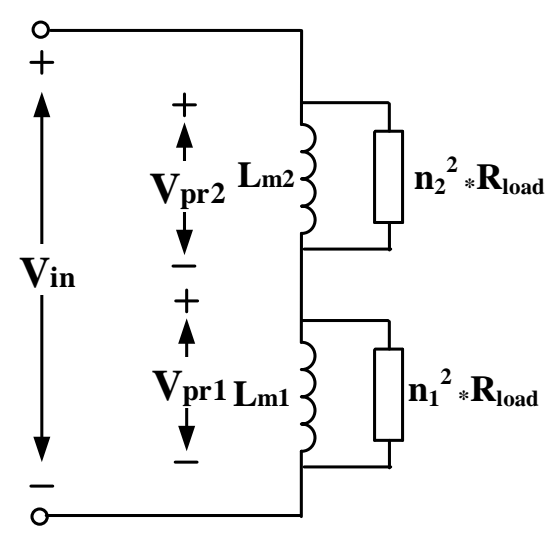

Figure 6. Equivalent circuit to show the voltage conversion ratio of the proposed LDC.

\subsubsection{Elimination of the Circulating Current}

In the conventional PSFB converter, the circulating current losses in the freewheeling interval reduces the power conversion efficiency, especially when the converter works with small effective duty, $D$. In contrast, the proposed converter can eliminate circulating current due to the additional snubber circuit composed of $C_{r 2}, D_{4}$ and $D_{5}$. Figure 7 shows the difference between the circulating current in the conventional PSFB and the proposed converter. As explained in the operation of mode 4 and mode 5 , since the resonant capacitor $C_{r 2}$ is discharged and the diodes $D_{1}$ and $D_{4}$ are forward biased the primary current is reduced quickly during the freewheeling period thereby reducing the circulating current. Consequently, ZCS turn-off can nearly be achieved for the lagging leg switches of the PSFB converter.

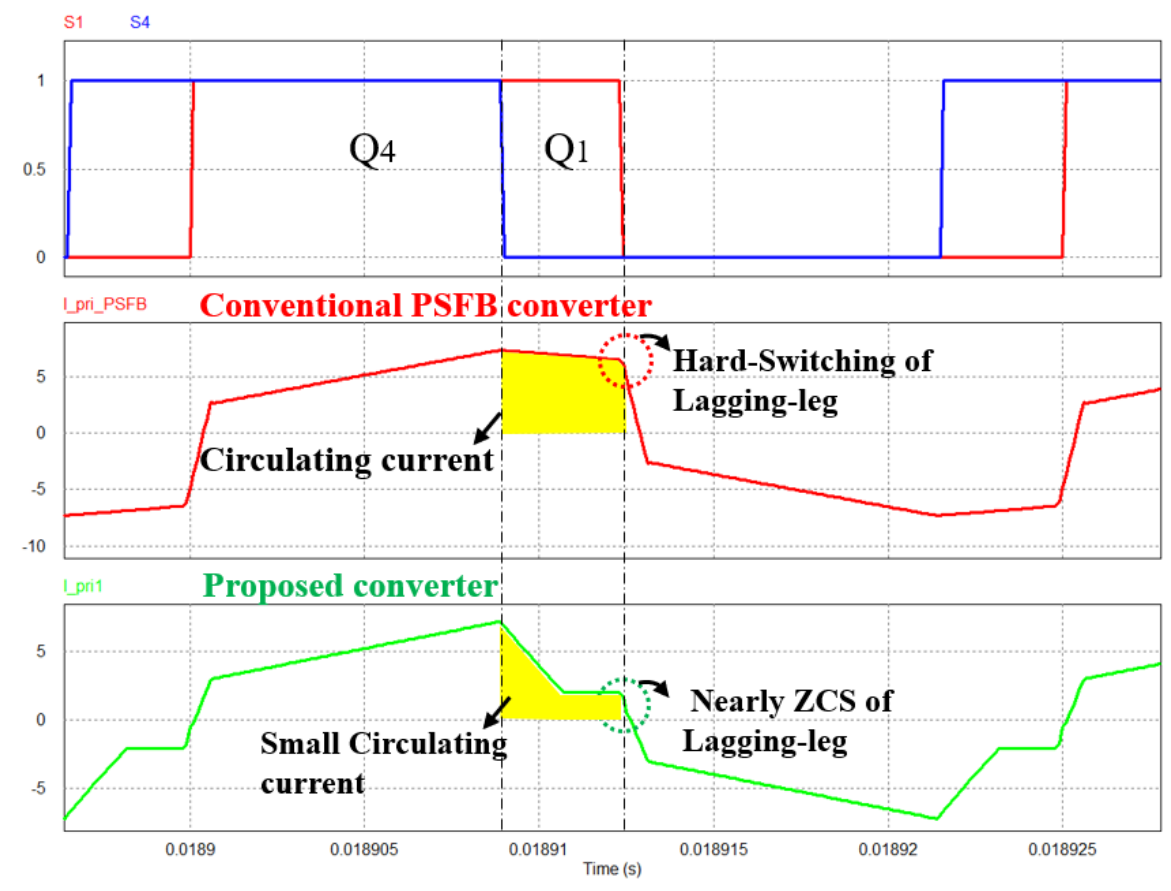

Figure 7. Comparison of the circulating current in the conventional PSFB converter and proposed converter. 


\subsubsection{Small Output Current Ripple}

In the conventional PSFB converter, the amplitude of the voltage applied to the output inductor in the powering period is the same as in the freewheeling period, as shown in Figure 8a. However, in the proposed converter, due to the operation of the forward converter, as explained in mode 5 to mode 7 , the voltage applied to the output inductor during the freewheeling period is reduced since the diode D5 is reverse biased, as shown in Figure $8 \mathrm{~b}$. As a result, the current ripple of the output inductor can be reduced significantly.

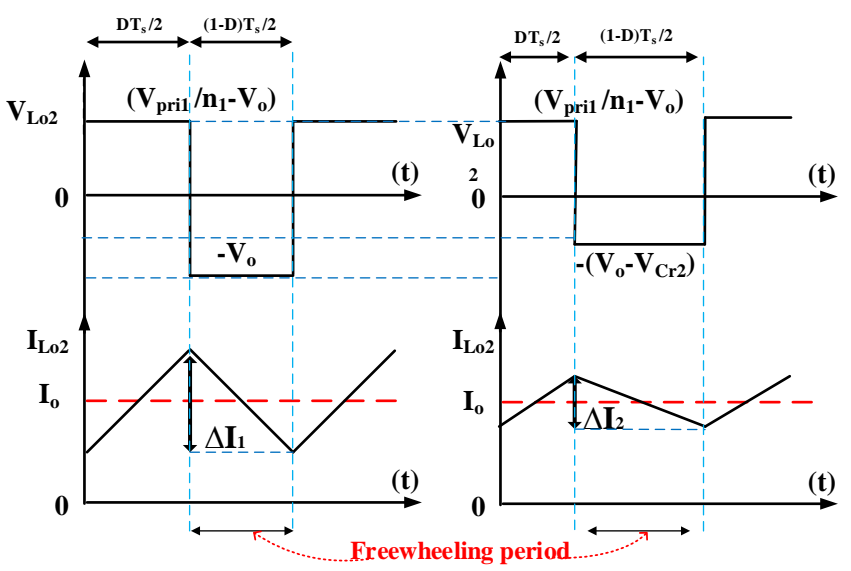

$\begin{array}{ll}\text { (a) Conventional PSFB converter } & \text { (b) Proposed converter }\end{array}$

Figure 8. Voltage and current waveforms at the output inductor of the conventional PSFB converter and the proposed converter.

In the conventional PSFB converter, the ripple current $\Delta I_{1(\text { Conventional_PSFB })}$ of the output inductor can be determined using (15).

$$
\Delta I_{1(\text { Convetional_PSFB })}=\frac{V_{o}\left(1-D_{e f f}\right) T_{S}}{2 L_{o 2}}
$$

The current ripple $\Delta I_{\text {2(Proposed_Converter) }}$ of the output inductor in the proposed converter can be calculated as in (16).

$$
\Delta I_{2(\text { Proposed_Converter })}=\frac{\left(V_{o}-V_{C r 2}\right)\left(1-D_{e f f}\right) T_{S}}{2 L_{o 2}}
$$

The ratio $R_{\text {ripple }}$ of the ripple of the current between these two cases can be calculated as in (17).

$$
R_{\text {ripple }}=\frac{\Delta I_{2}}{\Delta I_{1}}=\frac{V_{o}-V_{C r 2}}{V_{o}}=\frac{n_{2}}{n_{1} D_{e f f}+n_{2}\left(1-D_{e f f}\right)}
$$

Figure 9 illustrates the ratio of current ripple between two cases with different values of the effective duty cycles. When the voltage of the propulsion battery is $420 \mathrm{~V}$, the duty of the LDC is 0.9 and the current ripple of the output inductor $L_{O 2}$ of the proposed converter is just $29 \%$ of that of the conventional PSFB converter. When the voltage of the propulsion battery is $250 \mathrm{~V}$, the current ripple of the output inductor $L_{\mathrm{O} 2}$ is just $47 \%$ of that of the conventional PSFB converter. Therefore, the value and size of the output filter inductor $L_{\mathrm{O} 2}$ can be significantly reduced. 


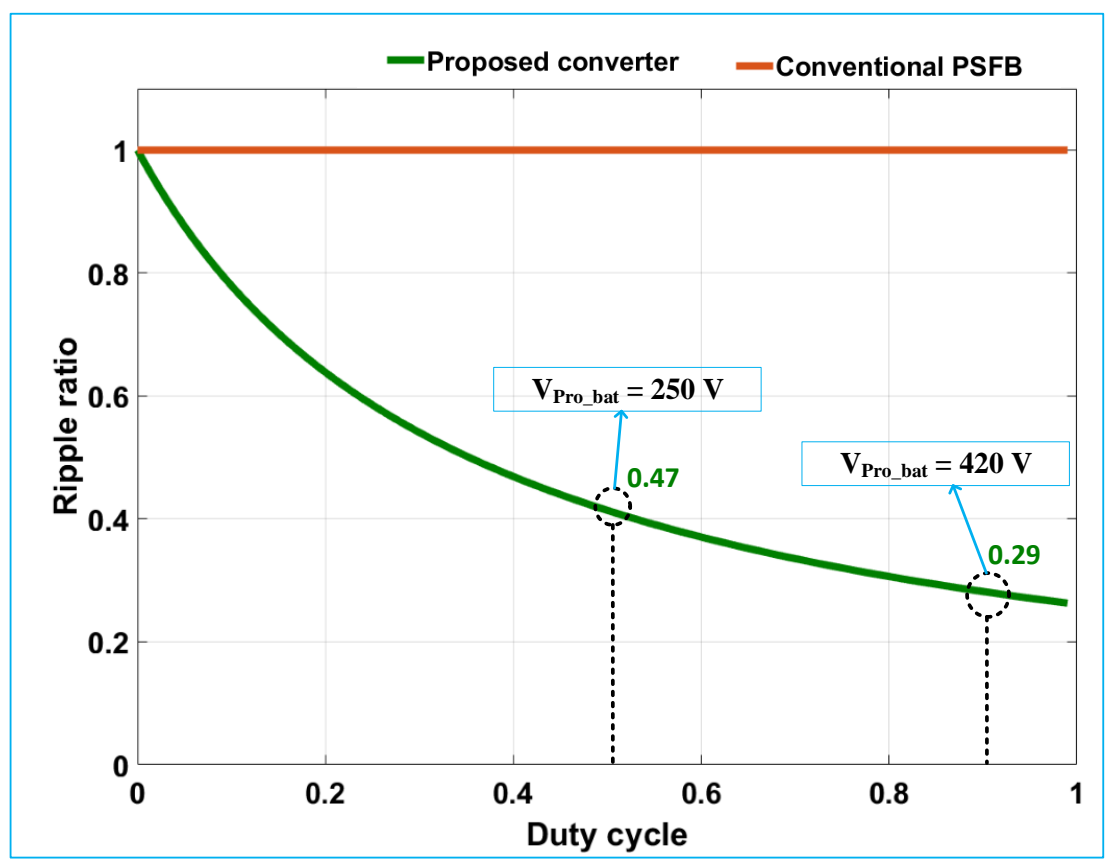

Figure 9. The ratio of the current ripple of the proposed converter compared to the conventional topology.

\subsection{Design Consideration}

3.2.1. ZVS Conditions for All of the Switches in the PSFB over the Full Load Range

In order to achieve ZVS turn-on for MOSFETs, the magnetizing current $i_{m 1}$ of $T R_{1}$ needs to be large enough. The magnetizing current and the energy stored in the magnetizing inductance of $T R_{1}$ can be determined as follows.

$$
\begin{gathered}
I_{m 1, \text { peak }}=\frac{V_{\text {Pro_bat }}}{L_{m 1}} \frac{T_{S}}{4} D_{\text {eff_min }} \\
E_{L_{m 1}}=\frac{1}{2} L_{m 1} I_{m 1, \text { peak }}^{2}=\frac{1}{2 L_{m 1}}\left(\frac{V_{\text {Pro_bat }} T_{S} D_{\text {eff_min }}}{4}\right)^{2}
\end{gathered}
$$

where $I_{m 1 \text {,peak }}$ is the peak value of the magnetizing current of $T R_{1} . T_{S}$ is the switching period and $D_{\text {eff_min }}$ is the minimum effective duty cycle of the PSFB converter.

To ensure the ZVS condition over the whole load range, the energy stored in the magnetizing inductance should be larger than that stored in the parasitic capacitors $C_{o s s}$ of MOSFETs.

$$
E_{L_{m 1}} \geq E_{C_{o s s}}=\frac{1}{2}\left(2 C_{o s s}\right) V_{\text {Pro_bat }}^{2}
$$

The required magnetizing inductance of TR1 can be calculated as in (21).

$$
L_{m 1} \leq \frac{1}{2 C_{\text {oss }}}\left(\frac{T_{s} D_{e f f \_m i n}}{4}\right)^{2}
$$

In addition to the condition in (21), the dead-time for the MOSFETs also needs to be satisfied (22).

$$
T_{\text {dead }} \leq \frac{\pi}{2} \sqrt{2\left(L_{L K 1}+L_{L K 2}\right) C_{o s s}}
$$

\subsubsection{Design of the Clamp and Resonant Capacitors}

As explained earlier in the operation of mode 7 , the capacitor $C_{r 1}$ resonates with the leakage inductance $L_{L K 2}$ and the magnetizing inductance $L_{m 2}$ of $T R_{2}$. Hence, the value of clamp capacitor $C_{r 1}$ can be calculated as in (23). However, since the voltage applied to the 
switches of PSFB converter increases due to the resonance, the resonant frequency needs to be selected much lower than the switching frequency in order to reduce it.

$$
C_{r 1}>>\frac{1}{\left(2 \pi f_{s}\right)^{2}\left(L_{L K 1}+L_{m 1}\right)}
$$

The resonant capacitor $C_{r 2}$ is the output capacitor of the forward converter. Thus, its value can be calculated using (24).

$$
C_{r 2}>\frac{n_{2} I_{o}\left(D_{e f f}+D^{\prime}\right)}{n_{1} f_{s} \Delta V_{C_{r 2}}}
$$

\section{Experimental Results}

In order to verify the performance of the proposed topology, a prototype converter was implemented. The specification of the proposed converter is shown in Table 1. All of the parameters for the transformer, inductor and capacitor are illustrated in Table 2. This paper focuses on illustrating the experimental results regarding function III of the proposed integrated OBC.

Table 1. Specification for the integrated OBC converter.

\begin{tabular}{ccc}
\hline Operation Condition & Parameter & Value [Unit] \\
\hline \multirow{2}{*}{ PFC stage } & AC voltage & $220[\mathrm{~V}] / 60[\mathrm{~Hz}]$ \\
& DC-link Voltage & $380-420[\mathrm{~V}]$ \\
& Rated power & $3.5[\mathrm{~kW}]$ \\
\hline & DC-link voltage & $380-420[\mathrm{~V}]$ \\
Function I: & Propulsion battery voltage & $250-420[\mathrm{~V}]$ \\
DC-link to propulsion battery & Rated power & $3.3[\mathrm{~kW}]$ \\
& Switching frequency & $30[\mathrm{kHz}]$ \\
\hline \multirow{2}{*}{ Function II: } & DC-link voltage & $380-420[\mathrm{~V}]$ \\
Propulsion battery to DC-link & Propulsion battery voltage & $250-420[\mathrm{~V}]$ \\
(OBC) & Rated power & $3.3[\mathrm{~kW}]$ \\
& Switching frequency & $30[\mathrm{kHz}]$ \\
\hline \multirow{2}{*}{ Function III: } & Propulsion battery voltage & $250-420[\mathrm{~V}]$ \\
Propulsion battery to auxiliary & Auxiliary battery voltage & $23-25[\mathrm{~V}]$ \\
battery (LDC) & Rated power & $1[\mathrm{~kW}]$ \\
& Switching frequency & $50[\mathrm{kHz}]$ \\
\hline
\end{tabular}

Table 2. Parameters of the circuit components.

\begin{tabular}{lc}
\hline \multicolumn{1}{c}{ Components } & Value \\
\hline All Switches $\left(S_{1} \sim S_{4}: Q_{1} \sim Q_{5}\right)$ & IPW65R041CFD \\
Turns ratio of the transformer $T R_{1}(1: \mathrm{n}: \mathrm{m})$ & $20: 23: 3$ \\
Leakage inductance of transformer $T R_{1}\left(L_{L K 1}\right)$ & $12.2[\mu \mathrm{H}]$ \\
Magnetizing inductance of transformer $T R_{1}\left(L_{m 1}\right)$ & $605[\mu \mathrm{H}]$ \\
Core size of $T R_{1}$ & $\mathrm{PQ72} / 52$ \\
Turns ratio of the transformer $T R_{2}\left(n_{2}\right)$ & $32: 16$ \\
Leakage inductance of transformer $T R_{2}\left(L_{L K 2}\right)$ & $16[\mu \mathrm{H}]$ \\
Magnetizing inductance of transformer $T R_{2}\left(L_{m 2}\right)$ & $452[\mu \mathrm{H}]$ \\
Core size of $T R_{1}$ & $\mathrm{PQ72} / 52$ \\
Clamp capacitor $\left(C_{r 1}\right)$ & $0.22[\mu \mathrm{F}]$ \\
Resonant capacitor $\left(C_{r 2}\right)$ & $100[\mu \mathrm{F}]$ \\
Diodes $\left(D_{1} \sim D_{2}\right)$ & $\mathrm{DSSK} 70-008 \mathrm{~A}$ \\
Diode $\left(D_{3} \sim D_{5}\right)$ & $\mathrm{DSSK} 60-0045 \mathrm{~B}$ \\
\hline
\end{tabular}

Figures 10 and 11 show the measured waveforms at the lagging switches and the leading switches with $400 \mathrm{~V}$ input, $25 \mathrm{~V}$ output and $1 \mathrm{~kW}$ output power. In Figure 10, it can 
be observed that the MOSFET $Q_{1}$ turns on with ZVS and turns off with nearly ZCS. There is a small negative current flowing through its body diode to maintain the zero voltage during the turn-on period. The turn-off current of $Q_{1}$ is just $0.5 \mathrm{~A}$, thus turn-off losses of the lagging leg MOSFETs are minimized. Figure 11 shows that MOSFET $Q_{3}$ is also turned on with ZVS condition.

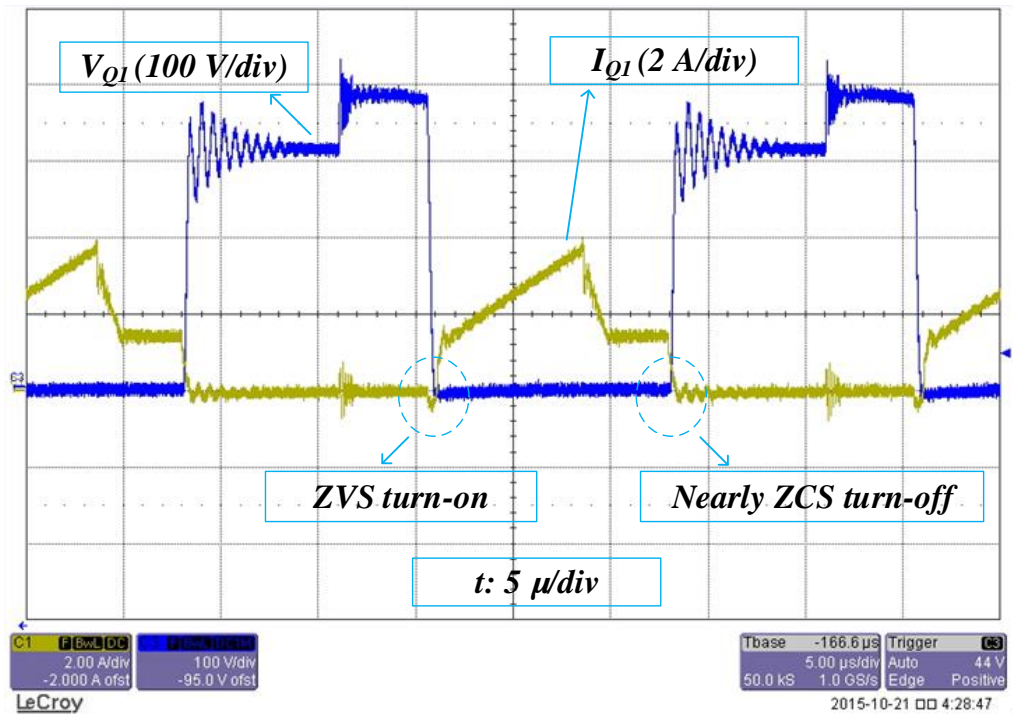

Figure 10. Voltage and current of switch $Q_{1}$ at $100 \%$ of load.

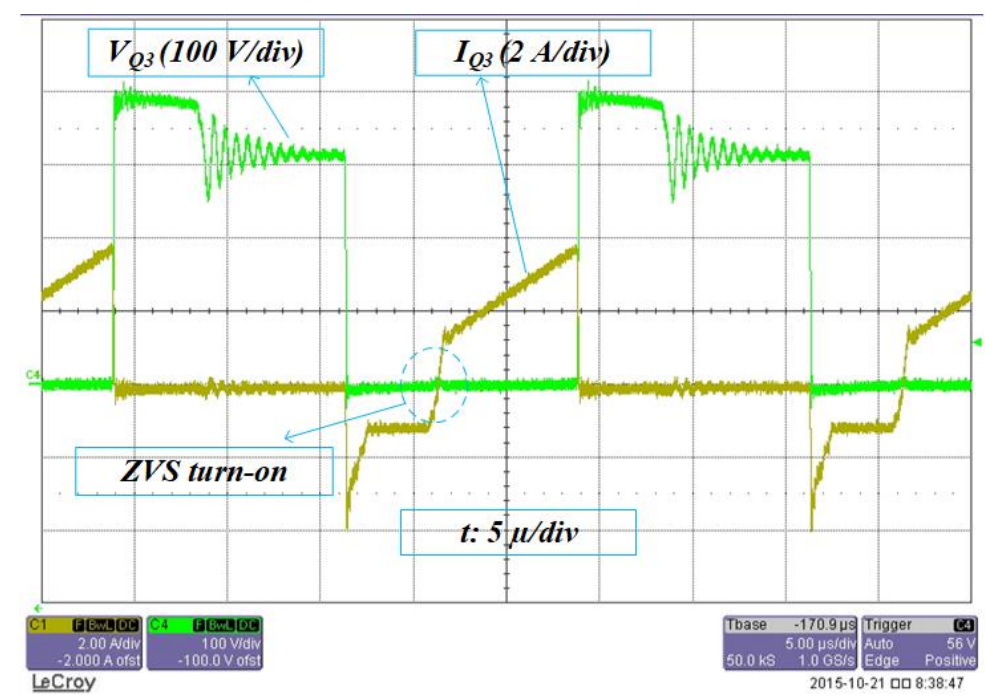

Figure 11. Voltage and current of switch $Q_{3}$ at $100 \%$ of load.

Figure 12 shows the waveform of MOSFET $Q_{1}$ at the light load condition (10\% load) with an input voltage of $330 \mathrm{~V}$ and output power of $100 \mathrm{~W}$. It can be clearly observed from Figure 12 that the lagging leg switches can maintain ZVS turn-on and nearly ZCS turn-off at light load condition. 


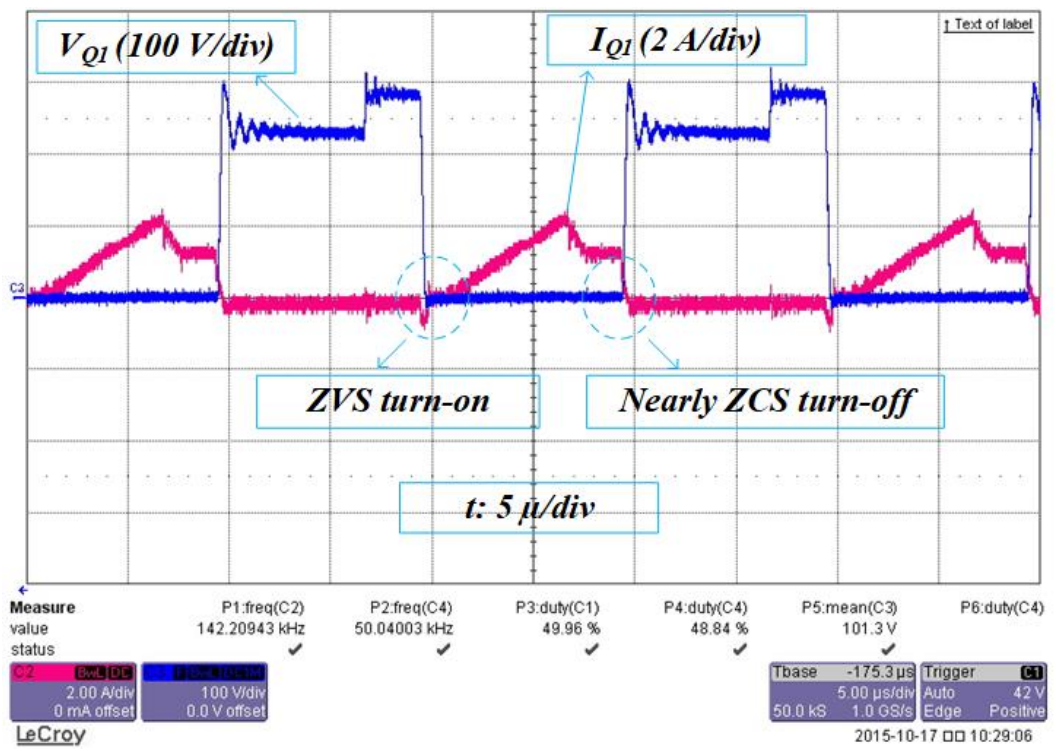

Figure 12. Voltage and current of switch $Q_{1}$ at $10 \%$ of load.

Figure 13 represents the voltage and current waveforms of the transformer $T R_{1}$. It can be observed that there is nearly no circulating current in the primary side of the transformer $T R_{1}$ during freewheeling interval.

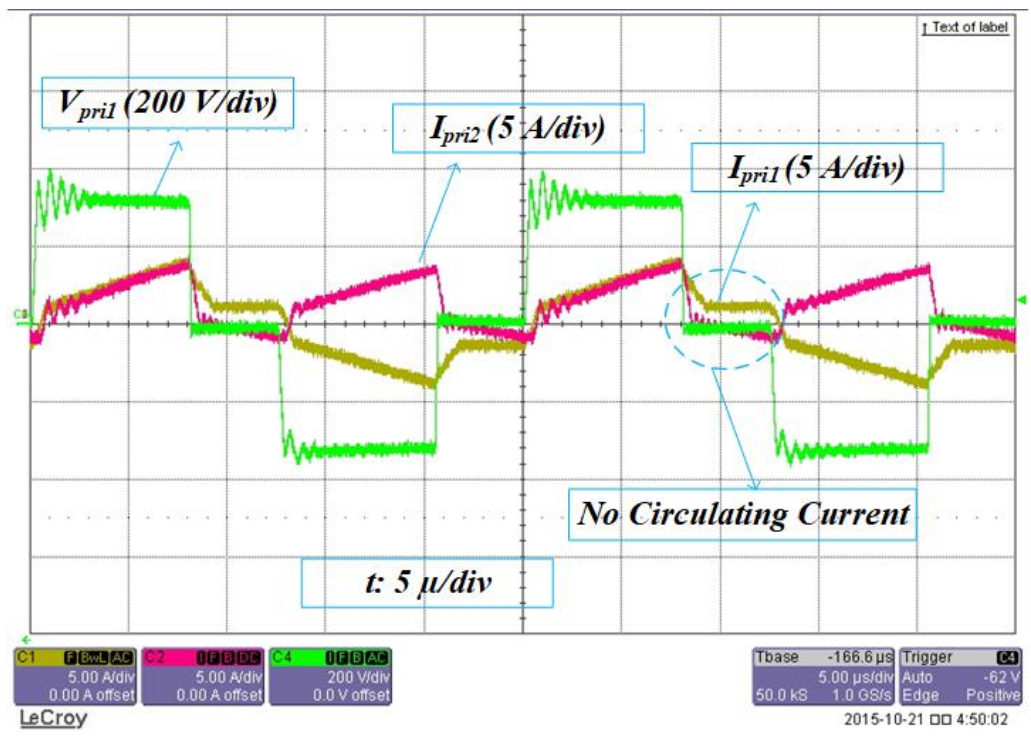

Figure 13. Voltage and current of transformer $T R_{1}$ at $100 \%$ of load.

The measured waveforms in Figure 14 depict the waveforms at the primary side of the transformer $T R_{2}$. We can see that the current of transformer $T R_{2}$ is reset by the active clamp circuit $Q_{5}$ and $C_{r 1}$. Figure 15 shows that both ZVS turn-on and ZCS turn-off can be achieved at the secondary rectifier diodes, hence there is no reverse recovery. In addition, the voltage at the rectifier diode is clamped around $80 \mathrm{~V}$ so that the diode with a lower voltage rating can be used. 


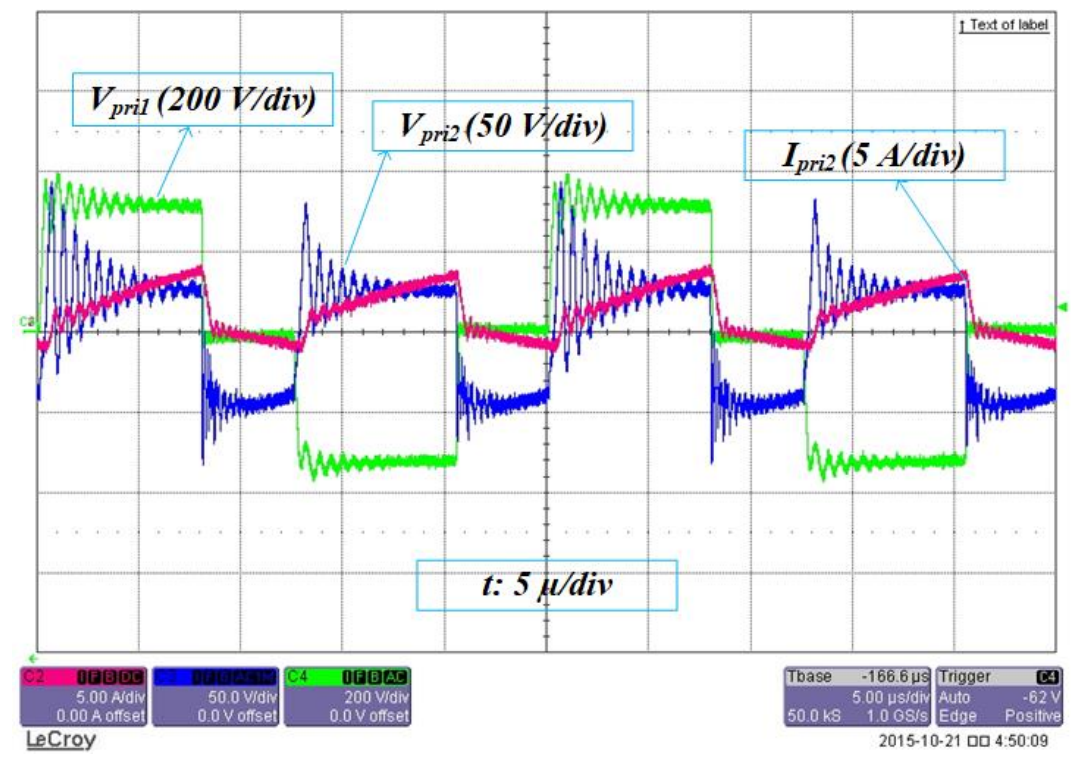

Figure 14. Voltage and current of transformer $T R_{2}$ at $100 \%$ of load.

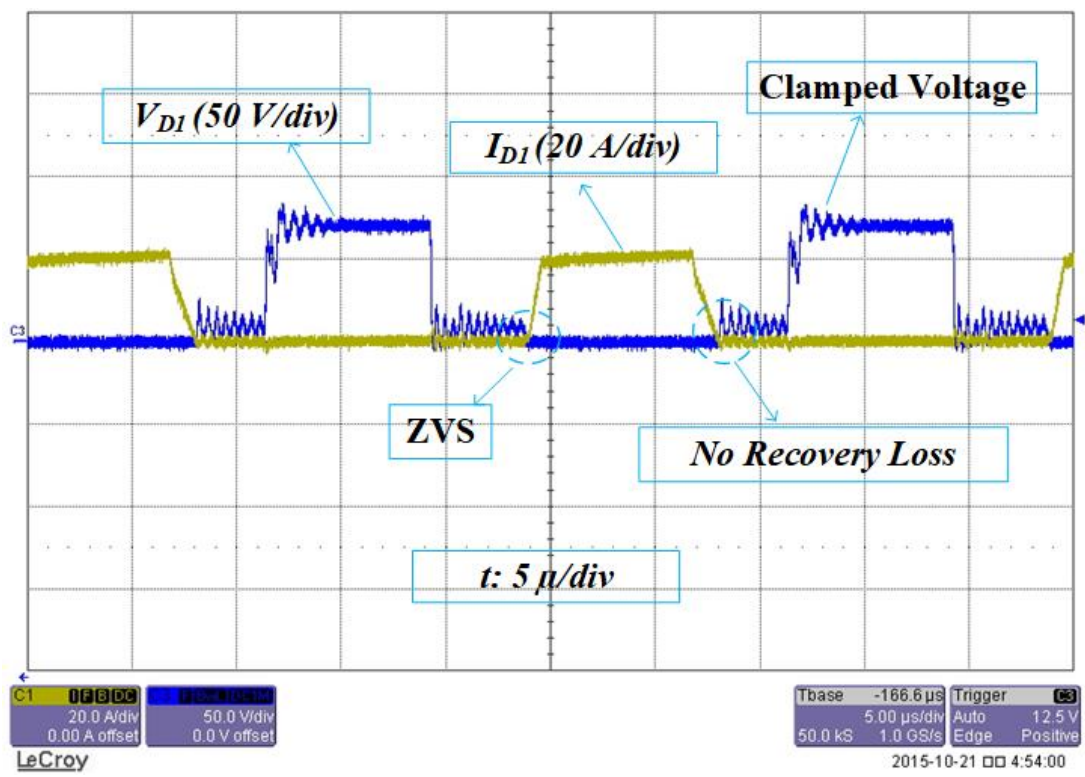

Figure 15. Voltage and current of diode $D_{1}$ at $100 \%$ of load.

The measured waveforms at diode $D_{3}$ are shown in Figure 16. It can achieve both ZVS turn-on and ZCS turn-off. The voltage across the diode $D_{3}$ oscillates due to the leakage inductance of the transformer $T R_{2}$. Figure 17 shows the current and voltage waveforms at the active clamp switch $Q_{5}$ with ZVS turn-on.

The measured waveforms at diode $D_{4}$ are shown in Figure 18. Both ZVS turn-on and ZCS turn-off are achieved at diode $D_{4}$, thus there is no recovery loss at this diode.

The efficiency during function III operation with a wide range of input voltage variation is measured and shown in Figure 19 with the wide input voltage variation from $290 \mathrm{~V}$ to $400 \mathrm{~V}$. The proposed converter shows a high efficiency all over the load range and the maximum efficiency is $96.03 \%$ at $500 \mathrm{~W}$, which is much higher than those of conventional ones in $[19,22,25]$. 


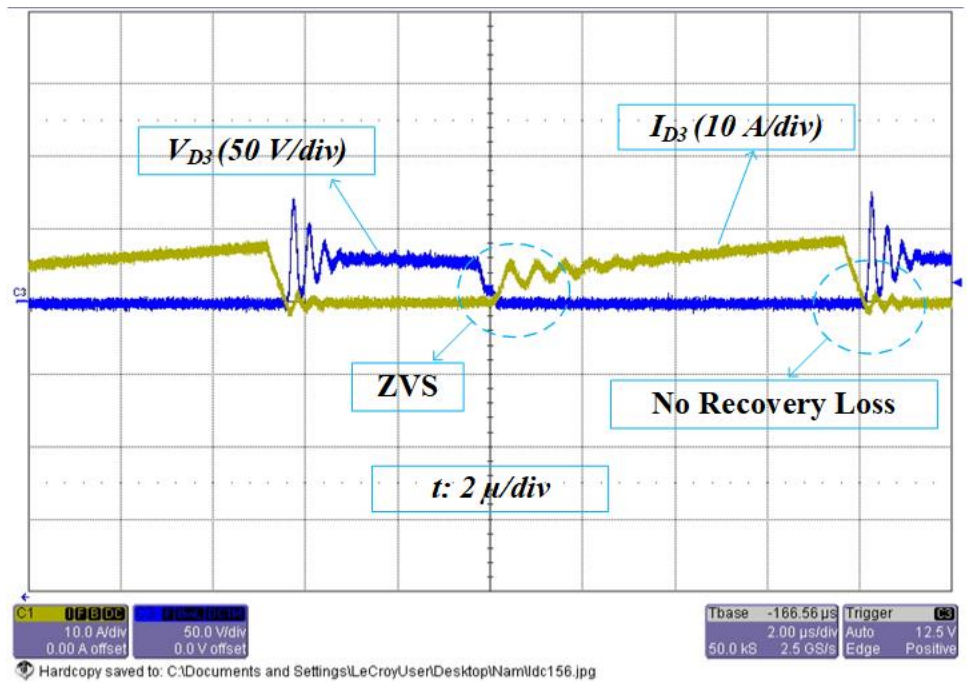

Figure 16. Voltage and current of diode $D_{3}$ at $100 \%$ of load.

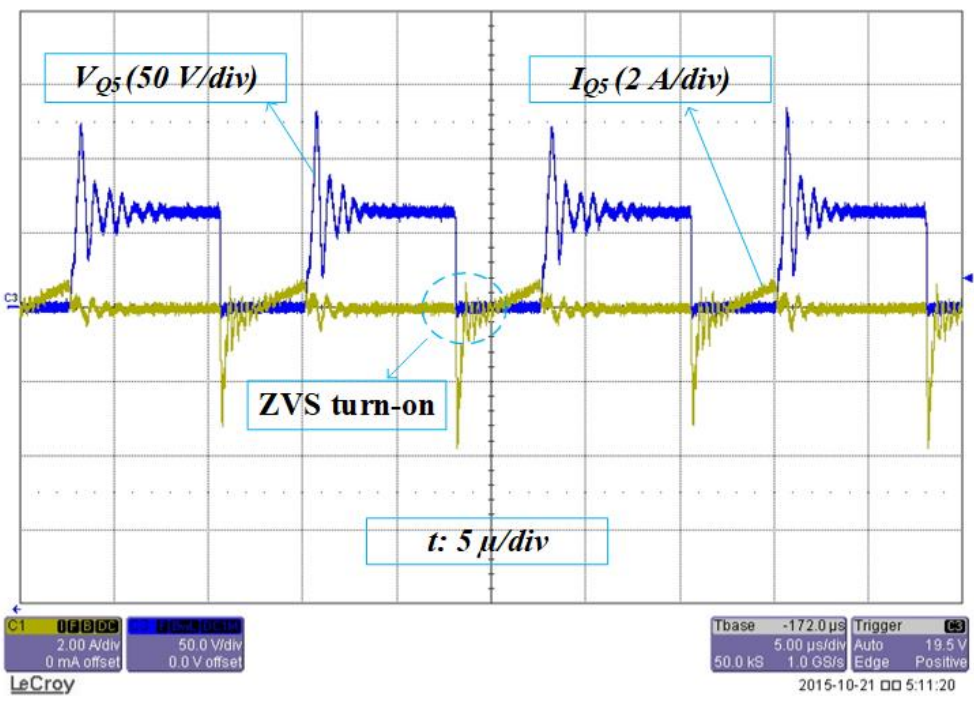

Figure 17. Voltage and current of switch $Q_{5}$ at $100 \%$ of load.

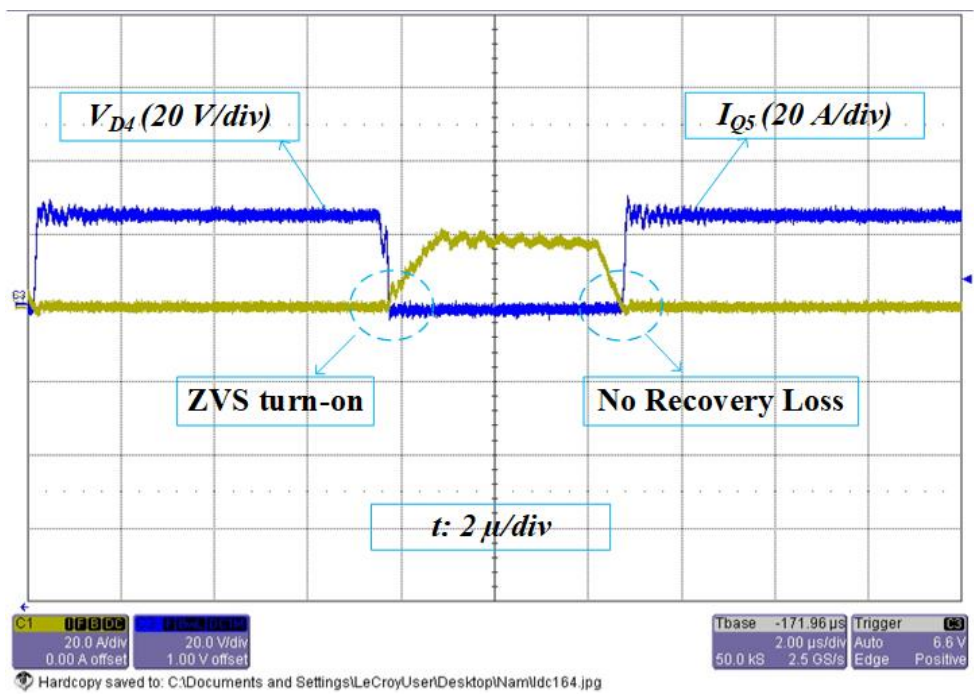

Figure 18. The voltage and current of diode $D_{4}$ at $100 \%$ of load. 


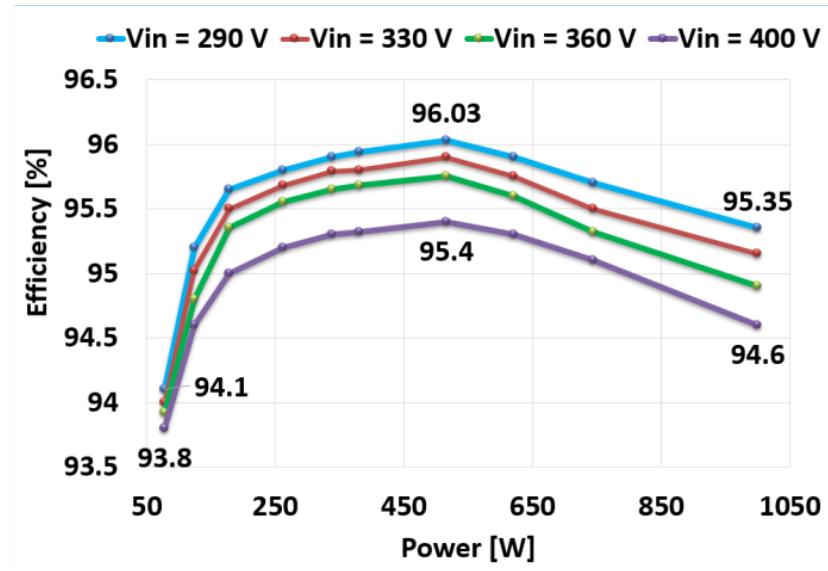

Figure 19. Efficiency plots during function III operation with wide range of input voltage variation.

The efficiency during function I and function II operations is also shown in Figures 20 and 21, respectively. In function $\mathrm{I}$, the maximum efficiency is $98.2 \%$ when $\mathrm{V}_{\mathrm{DC}}=400 \mathrm{~V}, \mathrm{~V}_{\mathrm{DC}}=420 \mathrm{~V}$ and $\mathrm{P}_{\mathrm{O} \_\mathrm{I}}=2.3 \mathrm{~kW}$. In function II, the maximum efficiency is $97.58 \%$ when $\mathrm{V}_{\mathrm{DC}}=400 \mathrm{~V}, \mathrm{~V}_{\text {Pro_Bat }}=420 \mathrm{~V}$ and $P_{\mathrm{O} \_I I}=1.8 \mathrm{~kW}$.

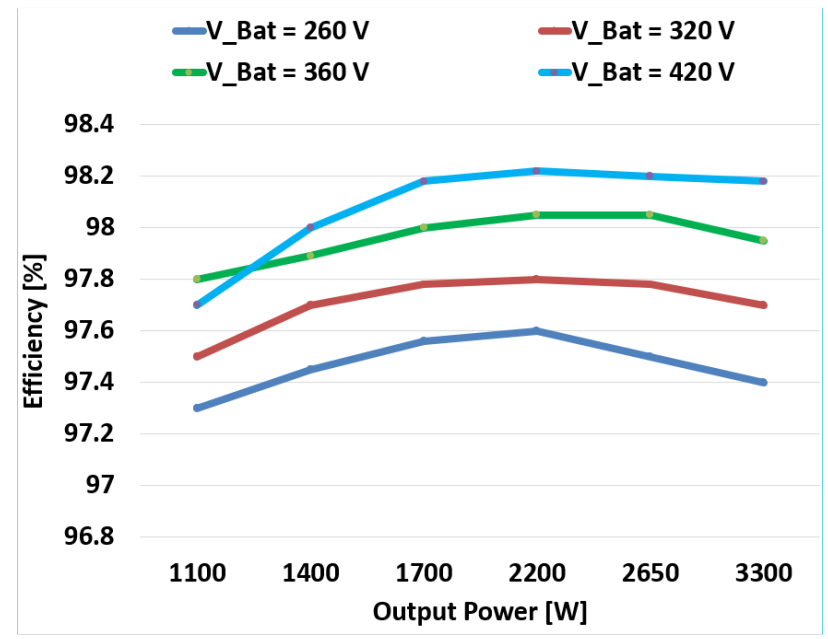

Figure 20. Efficiency plots during function I operation with wide range of input voltage variation.

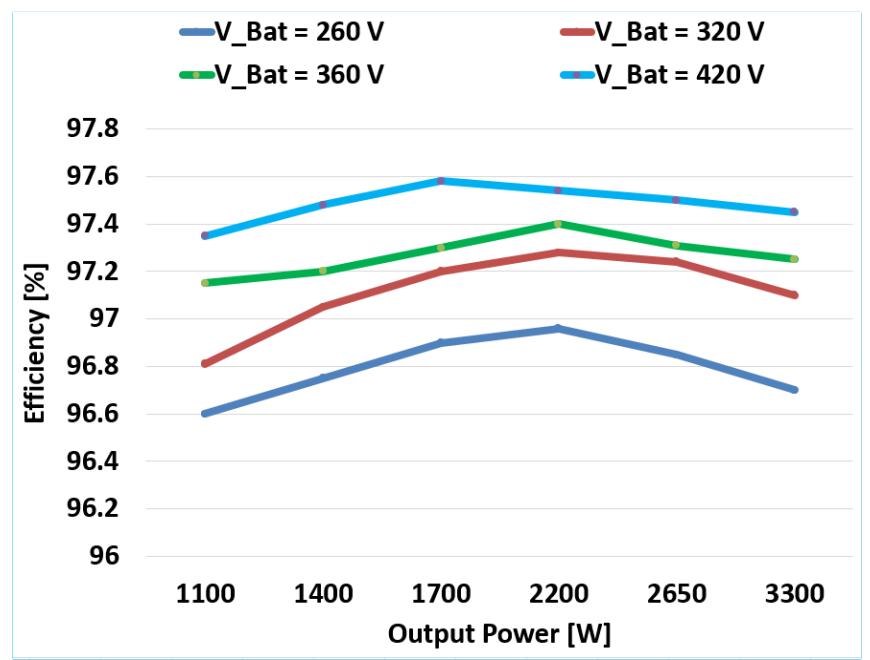

Figure 21. Efficiency plots during function II operation with wide range of input voltage variation. 


\section{Conclusions}

This paper has introduced a novel hybrid LDC converter for the integrated OBC using a combination of a PSFB converter and a forward converter. The proposed converter has a high voltage conversion ratio and a high efficiency characteristic due to the hybrid structure. The power is shared by two converters and hence the conduction loss is reduced. The efficiency of the proposed converter can be further improved due to the soft-switching characteristics throughout the load range. The proposed integrated OBC shows over $97 \%$ efficiency during function I operation, over $96 \%$ efficiency during function II operation and over 95\% efficiency during function III operation almost throughout the load range, respectively. In addition, the size of the output inductor can be reduced significantly due to the cascaded output capacitors of the proposed LDC converter. The circulating current is reduced by using the passive snubber circuit, which also helps clamp the voltage applied to the rectifier diodes. The cost and the volume of the OBC can be significantly reduced due to the integrated structure of the proposed converter, and the fuel economy of the electric vehicles can be improved due to its high efficiency characteristics throughout the load range.

Author Contributions: V.-H.N. wrote the original draft manuscript and designed the prototype of the proposed converter; D.-V.T. analyzed the proposed converter and revised the manuscript; W.C. reviewed the manuscript and supervised the research. All authors have read and agreed to the published version of the manuscript.

Funding: This research received no external funding.

Institutional Review Board Statement: Not applicable.

Informed Consent Statement: Not applicable.

Conflicts of Interest: The authors declare no conflict of interest.

\section{References}

1. He, T.; Lu, D.D.-C.; Wu, M.; Yang, Q.; Li, T.; Liu, Q. Four-Quadrant Operations of Bidirectional Chargers for Electric Vehicles in Smart Car Parks: G2V, V2G, and V4G. Energies 2021, 14, 181. [CrossRef]

2. Figueiredo, J.P.M.; Tofoli, F.L.; Silva, B.L.A. A Review of Single-Phase PFC Topologies Based on the Boost Converter. In Proceedings of the 2010 9th IEEE/IAS International Conference on Industry Applications-INDUSCON 2010, Sao Paulo, Brazil, 8-10 November 2010; pp. 1-6. [CrossRef]

3. Musavi, F.; Eberle, W.; Dunford, W.G. A High-Performance Single-Phase Bridgeless Interleaved PFC Converter for Plug-in Hybrid Electric Vehicle Battery Chargers. IEEE Trans. Ind. Appl. 2011, 47, 1833-1843. [CrossRef]

4. Musavi, F.; Eberle, W.; Dunford, W.G. A Phase Shifted Semi-Bridgeless Boost Power Factor Corrected Converter for Plug in Hybrid Electric Vehicle Battery Chargers. In Proceedings of the 2011 Twenty-Sixth Annual IEEE Applied Power Electronics Conference and Exposition (APEC), Fort Worth, TX, USA, 6-11 March 2011; pp. 821-828. [CrossRef]

5. Singh, B.; Singh, B.N.; Chandra, A.; Al-Haddad, K.; Pandey, A.; Kothari, D.P. A review of single-phase improved power quality AC-DC converters. IEEE Trans. Ind. Electron. 2003, 50, 962-981. [CrossRef]

6. Gautam, D.; Musavi, F.; Edington, M.; Eberle, W.; Dunford, W.G. An Automotive on-Board $3.3 \mathrm{~kW}$ Battery Charger for PHEV Application. In Proceedings of the 2011 IEEE Vehicle Power and Propulsion Conference, Chicago, IL, USA, 6-9 September 2011; pp. 1-6. [CrossRef]

7. Gautam, D.S.; Musavi, F.; Eberle, W.; Dunford, W.G. A Zero-Voltage Switching Full-Bridge DC-DC Converter with Capacitive Output Filter for Plug-In Hybrid Electric Vehicle Battery Charging. IEEE Trans. Power Electron. 2013, 28, 5728-5735. [CrossRef]

8. Averberg, A.; Meyer, K.R.; Mertens, A. Current-Fed Full Bridge Converter for Fuel Cell Systems. In Proceedings of the 2008 IEEE Power Electronics Specialists Conference, Rhodes, Greece, 15-19 June 2008; pp. 866-872. [CrossRef]

9. Yakushev, V.; Meleshin, V.; Fraidlin, S. Full-Bridge Isolated Current Fed Converter with Active Clamp. In Proceedings of the APEC '99. Fourteenth Annual Applied Power Electronics Conference and Exposition. 1999 Conference Proceedings (Cat. No.99CH36285), Dallas, TX, USA, 14-18 March 1999; Volume 1, pp. 560-566. [CrossRef]

10. Choi, H.S.; Kim, J.W.; Cho, B.H. Novel zero-voltage and zero-current-switching (ZVZCS) full-bridge PWM converter using coupled output inductor. IEEE Trans. Power Electron. 2002, 17, 641-648. [CrossRef]

11. Dudrik, J.; Trip, N. Soft-Switching PS-PWM DC-DC Converter for Full-Load Range Applications. IEEE Trans. Ind. Electron. 2010, 57, 2814. [CrossRef] 
12. Cho, J.G.; Rim, G.H.; Lee, F.C. Zero Voltage and Zero Current Switching Full Bridge PWM Converter using Secondary Active Clamp. In Proceedings of the PESC Record. 27th Annual IEEE Power Electronics Specialists Conference, Baveno, Italy, 23-27 June 1996; Volume 1, pp. 657-663. [CrossRef]

13. Zhang, X.; Chung, H.S.; Ruan, X.; Ioinovici, A. A ZCS Full-Bridge Converter without Voltage Overstress on the Switches. IEEE Trans. Power Electron. 2010, 25, 686-698. [CrossRef]

14. Tran, D.; Vu, N.; Choi, W. A Quasi-Resonant ZVZCS Phase-Shifted Full-Bridge Converter with an Active Clamp in the Secondary Side. Energies 2018, 11, 2868. [CrossRef]

15. Hiltunen, J.; Väisänen, V.; Juntunen, R.; Silventoinen, P. Variable-Frequency Phase Shift Modulation of a Dual Active Bridge Converter. IEEE Trans. Power Electron. 2015, 30, 7138-7148. [CrossRef]

16. Park, J.; Choi, S. Design and Control of a Bidirectional Resonant DC-DC Converter for Automotive Engine/Battery Hybrid Power Generators. IEEE Trans. Power Electron. 2014, 29, 3748-3757. [CrossRef]

17. Oh, C.; Kim, D.; Woo, D.; Sung, W.; Kim, Y.; Lee, B. A High-Efficient Nonisolated Single-Stage On-Board Battery Charger for Electric Vehicles. IEEE Trans. Power Electron. 2013, 28, 5746-5757. [CrossRef]

18. Yoo, K.; Kim, K.; Lee, J. Single- and Three-Phase PHEV Onboard Battery Charger Using Small Link Capacitor. IEEE Trans. Ind. Electron. 2013, 60, 3136-3144. [CrossRef]

19. Nguyen, H.V.; Lee, D.-C.; Blaabjerg, F. A Novel SiC-Based Multifunctional Onboard Battery Charger for Plug-In Electric Vehicles. IEEE Trans. Power Electron. 2021, 36, 5635-5646. [CrossRef]

20. Nguyen, H.V.; To, D.; Lee, D. Onboard Battery Chargers for Plug-in Electric Vehicles With Dual Functional Circuit for Low-Voltage Battery Charging and Active Power Decoupling. IEEE Access 2018, 6, 70212-70222. [CrossRef]

21. Nguyen, H.V.; Lee, D. An Improved Low-Voltage Charging Circuit for Single-Phase Onboard Battery Chargers. In Proceedings of the 2019 IEEE Applied Power Electronics Conference and Exposition (APEC), Anaheim, CA, USA, 17-21 March 2019; pp. 3325-3331. [CrossRef]

22. Kim, D.; Kim, M.; Lee, B. An Integrated Battery Charger with High Power Density and Efficiency for Electric Vehicles. IEEE Trans. Power Electron. 2017, 32, 4553-4565. [CrossRef]

23. Kim, S.; Kang, F. Multifunctional Onboard Battery Charger for Plug-in Electric Vehicles. IEEE Trans. Ind. Electron. 2015, 62, 3460-3472. [CrossRef]

24. Kim, S.Y.; Song, H.; Nam, K. Idling Port Isolation Control of Three-Port Bidirectional Converter for EVs. IEEE Trans. Power Electron. 2012, 27, 2495-2506. [CrossRef]

25. Kim, Y.; Oh, C.; Sung, W.; Lee, B.K. Topology and Control Scheme of OBC-LDC Integrated Power Unit for Electric Vehicles. IEEE Trans. Power Electron. 2017, 32, 1731-1743. [CrossRef] 